\title{
Aplicativos de Tradução Português-Libras na Educação Bilíngue de Surdos: tradução por meio de sinais ou datilologia?
}

Ygor Corrêa - PPG Design/UniRitter, correaygorprof@ gmail.com Rafael

Peduzzi Gomes - PPG Design/UniRitter, rafaelpeduzzi@gmail.com

Vinicius Gadis Ribeiro - PPG Design/UniRitter, vinicius@uniritter.edu.br

Resumo: Os aplicativos Hand Talk e ProDeaf Móvel, enquanto Tecnologias Assistivas, traduzem conteúdo de Língua Portuguesa (LP) para Língua Brasileira de Sinais (Libras). No entanto, a inserção destes aplicativos no contexto de Educação Bilíngue para surdos tem gerado críticas sobre traduções feitas por meio de datilologia, ou seja, soletração manual do alfabeto da Língua Portuguesa. Esta é uma pesquisa qualiquantitativa, baseada nas literaturas sobre Libras e Aprendizagem Móvel, que investiga a incidência de datilologia, a partir da análise da tradução de 724 termos, extraídos de apostilas para o ensino de Libras. Os resultados evidenciaram maior incidência de datilologia no aplicativo ProDeaf Móvel do que no Hand Talk, todavia, constatou-se a predominância de sinais em Libras. Deste modo, considera-se que os aplicativos podem, em contexto educacional, fomentar a ampliação do conhecimento linguístico em Libras. Palavras-chave: Educação Bilíngue, Libras, Aplicativos de Tradução.

\section{Portuguese-Libras Translation Apps in Bilingual Education for Deaf: translation by signs or fingerspelling?}

Abstract: Hand Talk and ProDeaf Móvel apps, as Assistive Technologies, translate content from the Portuguese Language (PL) into Brazilian Sign Language (Libras). However, the insertion of these applications in the context of Bilingual Education for the deaf has generated criticism about translations made using fingerspelling, that is, manual spelling of the Portuguese Language alphabet. This is a quali-quantitative research, based on the literatures of Libras and Mobile Learning, which investigates the incidence of fingerspelling, considering the analysis of the conversion of 724 terms extracted from Libras textbooks for the teaching of Libras. The results evidenced a higher incidence of fingerspelling in the ProDeaf Movel app and lower in Hand Talk, revealing, by the other side, the predominance of signs in Libras. Thus, we considered that the applications can, in educational context, foster the expansion of the linguistic knowledge in Libras.

Keywords: Bilingual Education, Libras, Translation Apps.

\section{Introdução}

A partir de 2012, tem-se o surgimento de Tecnologias Assistivas (TAs) como os aplicativos Hand Talk e ProDeaf Móvel ${ }^{1}$, gratuitos e utilizados via dispositivos móveis, os quais propõem o rompimento de barreiras na comunicação entre sujeitos surdos e ouvintes, por meio da tradução automática de palavras e pequenas frases, de Língua Portuguesa para Língua Brasileira de Sinais (Libras). Uma vez que tais aplicativos são suportados por dispositivos móveis do tipo smartphone ou tablets, se está levando em consideração o status quo destes no contexto tecnológico, a saber, pelo fato de que a Fundação Getúlio Vargas de São Paulo (FGV-SP, 2018) aponta que o número de smartphones no Brasil já ultrapassou 220 milhões de aparelhos em 2018, aspecto que tem desencadeado mudanças comportamentais.

Durante a realização de uma pesquisa-base sobre o uso de aplicativos de tradução na Educação Bilíngue de Surdos com professores de uma escola municipal 
bilíngue de ensino fundamental (Educação Básica), situada na região metropolitana da grande Porto Alegre, constatou-se no discurso dos docentes críticas associadas à presença de datilologia nas traduções feitas pelos aplicativos Hand Talk e ProDeaf Móvel. Isso porque a datilologia é um recurso utilizado por falantes de línguas de sinais e não é uma língua, e sim um código de representação de letras alfabéticas.

O alfabeto manual é utilizado na interação entre usuários de língua de sinais para soletrar nomes próprios de pessoas ou lugares, siglas e algum vocábulo não existente na língua de sinais que ainda não tenha um sinal (Gesser, 2009). Neste horizonte, espera-se que os aplicativos em análise traduzam conteúdo para sinais próprios do léxico da Libras e não para datilologia. Infere-se que é relevante analisar implicações linguísticas relativas às referidas ferramentas digitais, segundo postulações apresentadas por autores como Corrêa et al. (2014a, 2014b), Vieira et al. (2014a, 2014b, 2014c), Corrêa, Gomes e Ribeiro (2017) e Corrêa, Gomes e Cruz (2018), a fim de sugerir possíveis aprimoramentos. Frente às críticas e a fím de verificar a efetiva incidência de datilologia, ou seja, soletração manual do alfabeto da Língua Portuguesa, nos aplicativos Hand Talk e ProDeaf Móvel, conduziu-se o presente estudo, sob a forma de uma pesquisa quali-quantitativa exploratória (Sampieri; Collado; Lucio, 2013), quando da análise da tradução de 724 termos, extraídos de quatro apostilas direcionadas ao ensino e à aprendizagem de Libras.

O referencial teórico deste estudo está embasado nas literaturas sobre Libras (Brasil, 2002; Quadros; Karnopp, 2004; Gesser, 2009), para fins de compreensão da inserção de Tecnologias Assistivas Digitais (Brasil, 2009; Bersch; Tonolli, 2006) como Hand Talk e ProDeaf Móvel, sob a perspectiva da Aprendizagem Móvel (Danesh, 2001; Consolo; Silva, 2008) com a abordagem BYOD (Bring Your Own Device), do inglês Traga seu Próprio Dispositivo (Vieira; Conforto, 2015), na Educação Bilíngue para Surdos (Cruz; Araújo, 2016; Casalli; Costa, 2017; Silva, 2015; Rangel; Stumpf, 2015, Kelman, 2015). O presente estudo está divido em 1. Introdução; 2. Libras ou Datilologia: implicações linguísticas; 3. Tecnologias Assistivas na Educação Bilíngue para Surdos; 4. Hand Talk e ProDeaf Móvel: da comunicação à aprendizagem móvel; 5. Metodologia; 6. Análise de dados; 7. Considerações finais; e Referências.

\section{Libras ou Datilologia: implicações linguísticas}

Nesta seção apresenta-se o que se entende por Língua Brasileira de Sinais (Libras) e datilologia. A Libras é uma língua natural, de modalidade visuoespacial, que surge na comunidade surda e que pode ser analisada em todos os níveis estruturais linguísticos (fonético, fonológico, semântico, sintático e pragmático), segundo Quadros e Karnopp (2004). Ainda acerca da definição de Libras, as autoras a definem como dotada de um léxico próprio, que é articulado através das mãos (expressões manuais), assim como expressões não manuais (faciais e corporais) sendo independente da Língua Portuguesa oral. Os sinais em Libras são formados por unidades mínimas ou parâmetros, a saber: configuração de mão; locação ou ponto de articulação; movimento; orientação da palma da mão; e expressões não manuais (ENM), tais como, movimentos do tronco, dos ombros, da boca e direção do olhar.

A Libras, enquanto língua natural da comunidade surda, foi reconhecida oficialmente em 2002 pela Lei $\mathrm{N}^{\circ} 10.436$ (Brasil, 2002), que a define como sistema linguístico de natureza visual-motora, com estrutura gramatical própria, enquanto meio legal de comunicação e expressão dos surdos brasileiros. Essa lei garante que a Libras seja parte integrante dos Parâmetros Curriculares Nacionais - PCNs, porém, não podendo substituir a Língua Portuguesa escrita, condição que implica na oferta de ensino bilíngue para surdos no Brasil (Cruz; Araújo, 2016; Casalli; Costa, 2017). 
Segundo Kelman (2015), o bilinguismo é a oferta de duas línguas, no caso da comunidade surda, nos processos de aprendizagem de Libras como primeira língua e de Língua Portuguesa enquanto segunda língua. A autora define um bom programa de ensino bilíngue como sendo aquele que apresenta duas características básicas: “(...) a combinação do ensino de conteúdos na língua materna e o desenvolvimento no letramento. Esses dois aspectos ajudam, de forma substancial, a aquisição de proficiência na segunda língua" (Kelman, 2015, p. 63).

A datilologia ou soletração manual do alfabeto da Língua Portuguesa é um código baseado nas línguas orais. A datilologia é adotada pelos usuários de línguas de sinais, neste caso, da Libras, em situações específicas e sempre que necessário para informar um nome ou objeto, que não possui sinal ou que não é conhecido por quem sinaliza em Libras (Quadros; Karnopp, 2004). Portanto, diante da existência de um item lexical (sinal) na Libras não é necessário fazer uso de datilologia. Assim, se os agentes animados virtuais 3D dos aplicativos Hand Talk e ProDeaf Móvel produzirem a soletração manual de palavras que possuem sinais equivalentes em Libras, não estará sendo disponibilizada a tradução adequada, mas a correspondência de letras da palavra na LP com a datilologia. A seguir, são apresentadas as noções referentes a Tecnologias Assistivas na educação para surdos.

\section{Tecnologias Assistivas na Educação Bilíngue para Surdos}

O conceito de Tecnologia Assistiva (TA), enquanto área de conhecimento interdisciplinar (Brasil, 2009), adotado neste estudo, está alicerçado na concepção de Cook e Hussey (1995), que definem que a TA visa a reduzir limitações de pessoas com deficiência, das mais variadas ordens, por meio de equipamentos, serviços, estratégias e práticas. Esta redução tem por objetivo promover a autonomia, a qualidade de vida e a inclusão dos indivíduos na sociedade, de modo que suas interações ocorram de forma mais equânime (Bersch; Tonolli, 2006). Em geral, as TAs dividem-se em dois tipos: recursos materiais (ponteiras, viseiras, etc) e recursos imateriais (sintetizadores de voz, softwares/aplicativos, etc). Este estudo foca-se em recursos digitais, sob a forma de aplicativos para surdos, e investiga essa temática, primeiro porque o surgimento de TAs digitais conversoras de Língua Portuguesa para Libras, utilizadas via dispositivos móveis, como smartphones e tablets, é recente. E, segundo, pelo fato de que estudos correlatos ao tema (Corrêa et al., 2014a, 2014b; Vieira et al., 2014a, 2014b, 2014c) têm evidenciado que tecnologias digitais conversoras para surdos apresentam potencialidades, assim como algumas fragilidades a serem superadas diante da recente oferta gratuita deste tipo de recurso na internet.

Não obstante aos aspectos mencionados, infere-se a partir de Silva (2015) que práticas pedagógicas apoiadas em recursos digitais podem ser instigantes, de modo que se considera, assim como Soares (2015), que o contexto de Educação Bilíngue para surdos deve promover a inserção de novas tecnologias digitais como forma de fomentar processos de autonomia e de inserção social. Silva (2015, p. 101) defende o uso de tecnologias digitais no contexto educacional de surdos, colocando que talvez "os instrumentos de nosso tempo possam facilitar o nosso processo de aprendizagem", partindo da premissa de que inserir uma tecnologia na sala de aula deve privilegiar a construção de um novo modelo de ensino e aprendizagem. Em consonância com as postulações apresentadas, Rangel e Stumpf (2015) consideram necessário que as práticas educacionais bilíngues de ensino e aprendizagem devem contemplar o uso de tecnologias desenvolvidas sob o viés da Informática na Educação para surdos. Deste modo, depreende-se que tecnologias digitais direcionadas à inclusão podem permitir que pessoas pertencentes a minorias linguísticas, como é o caso dos sujeitos surdos, 
possam vivenciar práticas escolares e cotidianas em Libras, seja para a comunicação ou para o estudo da língua (Corrêa et al., 2014a, 2014b; Vieira et al., 2014a, 2014b). Na próxima seção são apresentados os aplicativos Hand Talk e ProDeaf Móvel disponíveis para o público surdo e ouvinte.

\section{Hand Talk e ProDeaf Móvel: da comunicação à aprendizagem móvel}

Os aplicativos Hand Talk e ProDeaf Móvel são ferramentas digitais gratuitas, provenientes de pesquisas conduzidas no nordeste brasileiro, os quais traduzem de Língua Portuguesa, escrita ou falada, palavras, frases ou pequenos parágrafos para Libras, por meio de um agente animado virtual em 3D. Esses aplicativos são compatíveis com a maioria dos sistemas operacionais de smartphones e tablets, atualmente, disponíveis. Ambos os aplicativos podem funcionar parcialmente sem conexão à Internet e capturam texto e voz, porém, apresentam algumas diferenças quanto às funcionalidades que as constituem, como, por exemplo, em relação à escolha pela velocidade e rotação do agente animado virtual em $3 \mathrm{D}$, dicionário e vídeos temáticos (Corrêa; Gomes; Cruz, 2018) .

A proposta inicial dos aplicativos era o rompimento de barreiras comunicacionais entre surdos e ouvintes. Entretanto, esta proposta vem se modificando para além de situações de comunicação, pois o uso de aplicativos em pauta também enquadram-se na perspectiva da Aprendizagem Móvel, do inglês Mobile Learning ou m-learning (Danesh, 2001; Consolo; Silva, 2008), como desdobramento do e-learning aprendizagem por meio eletrônico. A aprendizagem Móvel, possibilita que alunos e professores, a partir de dispositivos móveis, possam acessar, visualizar e escolher conteúdos, estratégias e materiais para ensino e aprendizagem, por meio de aplicativos ou páginas de Internet. Dessa forma, esses usuários por meio de suas tecnologias possuem acesso em qualquer tempo e espaço ao conteúdo que desejam. No entanto, segundo Corrêa et al. (2014a), “(...) muitas escolas brasileiras ainda não possuem acesso à Internet ou não disponibilizam acesso a todos os seus espaços", portar um dispositivo móvel de propriedade pessoal significa não limitar-se à infraestrutura da escola, seja pelo tipo de conexão ou aparelho.

Na dinâmica da Aprendizagem Móvel, tem-se, segundo Vieira e Conforto (2015, p. 82), a popularização da sigla BYOD (Bring Your Own Device), do inglês Traga seu Próprio Dispositivo, que de acordo com as autoras "explora as tecnologias heterogêneas dos próprios estudantes para finalidades diversas, dentre as quais se destacam os smartphones", reduzindo custos para instituições educacionais e órgãos governamentais, além de propiciar o desencadeamento de um novo panorama na Informática Educativa. Estão associados à aprendizagem móvel, via BYOD (Vieira; Conforto, 2015, p. 84), elementos que a caracterizam como: "ubíqua (disponível em qualquer lugar); pervasiva (transparente e integrada às atividades cotidianas); e de ambiente (naturalmente entrelaçada ao entorno educacional)". Corrêa et al. (2014a, p. 7) referem-se ao fato de que o smartphone já está "inserido no cotidiano da sociedade contemporânea digital". Logo, sua utilização não exige do usuário outros saberes operacionais para fins de uso de aplicativos, senão aqueles já constitutivos do dia a dia.

Conforme mencionado na seção de Introdução, autores como Corrêa et al. (2014a, 2014b), Vieira et al. (2014a; 2014b; 2014c), Corrêa, Gomes e Ribeiro (2017) e Corrêa, Gomes e Cruz (2018) têm evidenciado potencialidades e fragilidades linguísticas e tecnológicas acerca dos aplicativos Hand Talk e ProDeaf Móvel. No que tange às potencialidades, há referências sobre autonomia, ampliação do conhecimento linguístico (Libras e Língua Portuguesa), socialização e construção da identidade do sujeito surdo. Quanto às fragilidades, os estudos enfatizam a demanda por 
aprofundamento quanto a parâmetros relativos a expressões não manuais e sobre a presença de datilologia no processo automático de sinalização. Apresenta-se, a seguir, a metodologia de pesquisa.

\section{Metodologia}

O presente estudo é proveniente de uma pesquisa de inserção dos aplicativos Hand Talk e ProDeaf Móvel em contexto de Educação Bilíngue, desenvolvida em uma escola municipal de ensino fundamental bilíngue, situada na região metropolitana de Porto Alegre (RS). A escolha pelos aplicativos citados está pautada nas postulações apresentadas por Vieira et al. (2014c), no que se refere à robustez tecnológica destas ferramentas digitais. Para fins de operacionalização do tema do presente estudo, levouse em consideração a participação de dez professores, com faixa etária entre 28 e 55 anos, sendo 8 ouvintes e 2 surdos, todos com formação em Libras. Estes professores responderam a um questionário semiestruturado, composto por questões abertas e fechadas, de onde foram extraídas narrativas referentes à presença de datilologia no processo de sinalização dos aplicativos aqui analisados. Foram coletadas e analisadas 10 narrativas, a partir da metodologia de Análise de Conteúdo (Bardin, 2007), estratégia que permitiu identificar 8 narrativas, contendo um total de 15 fragmentos discursivos com o termo datilologia. Ressalta-se que uma narrativa pode apresentar um ou mais fragmentos discursivos sobre o mesmo termo.

A metodologia adotada é exploratória (Sampieri; Collado; Lucio, 2013), posto que envolve um tema recente e interdisciplinar, que abarca áreas como Educação, Linguística e Tecnologia. Segundo os autores, é necessário familiarizar-se com o assunto, de modo que este tipo de pesquisa demanda: a) levantamento bibliográfico; b) entrevistas com pessoas sobre o tema; e c) interpretação de estratégias para a compreensão do tema. Na seção de análise de dados são apresentados: (1) os fragmentos discursivos dos professores a respeito de episódios de datilologia, os quais apresentam referência à presença majoritária de traduções automáticas com datilologia em vez de sinais e (2) a descrição do processo de análise de 724 termos, extraídos de 4 apostilas de nível básico de Libras. O processo de análise contou com a colaboração de três pesquisadores, número coerente de avaliadores, segundo Barbosa e Silva (2010), dentre esses, um linguista, um designer de interfaces e uma professora/intérprete de Libras. Os pesquisadores analisaram, individualmente, cada aplicativo, inserindo cada termo em Língua Portuguesa e registrando-o como convertido na forma de sinal ou datilologia. Posteriormente, os registros foram compilados, de modo a se obter um relatório único.

Relativo à análise conduzida, os pesquisadores inseriram, de modo digitado, em cada aplicativo os 724 termos isolados em Língua Portuguesa, oriundos de quatro apostilas de nível básico de Libras (I; II; III; IV), elaboradas pelo Centro de Capacitação de Profissionais da Educação e de Atendimento às Pessoas com Surdez (CAS) em parceria com o Ministério da Educação e Cultura (MEC) $)^{2}$. As quatro (4) apostilas possuem abordagens teórico-didáticas, seguidas de lista de termos associados a um conteúdo temático. Em cada seção, tem-se o título do tema, a imagem de um intérprete humano sinalizando determinado termo e junto a essa uma descrição em Língua Portuguesa dos parâmetros linguísticos que compõem o sinal. No que concerne ao tratamento dos dados, optou-se por desconsiderar três termos repetidos nas apostilas, e duas unidades temáticas da apostila 3, a saber: Locais de Goiânia e Cidades de Goiás, as quais apresentavam termos entendidos como regionais. A seguir, apresenta-se a análise de dados. 


\section{Análise de dados}

Como mencionado na metodologia do estudo, as narrativas dos professores foram analisadas por meio da Análise de Conteúdo (Bardin, 2007), a qual permitiu identificar referências a episódios datilológicos, oriundos do processo de sinalização, representado pelos agentes animados virtuais 3D dos aplicativos, corroborando as inferências de Corrêa et al. (2014a, 2014b) e Vieira et al. (2014b) quanto a essa questão. Desta forma, são apresentados alguns excertos (Quadro 1), inalterados quanto à forma e ao conteúdo.

Quadro 1 - Fragmentos discursivos de professores sobre datilologia

"Eu utilizo os aplicativos para consulta, mas tenho a impressão de que são
deficitários, pois têm datilologia na sinalização." (Professora ouvinte)
“Já fiz uso dos aplicativos em sala de aula, mas vi datilologia na hora de
mostrar para a turma." (Professora ouvinte)
“Acho que essas ferramentas auxiliam o aluno e o professor, porém quando têm
datilologia para um sinal conhecido, fica complicado." (Professora ouvinte e
Intérprete)
"Eu ver alfabeto manual, não ser bom, às vezes." (Professor surdo)
"Com frequência utilizo, porém tenho consciência que têm datilologia."
(Professora ouvinte)

Fonte: Coleta de dados da pesquisa.

Ambos os aplicativos apresentaram problemas técnicos na animação dos agentes animados virtuais em 3D, não manifestando sinal ou datilologia para os termos câncer (ProDeaf - Apostila 3) e meios de comunicação (Hand Talk - Apostila 4), portanto, excluídos da elaboração dos gráficos. Essa escolha deu-se a fim de permitir uma melhor visualização dos dados, visto que representavam somente cerca de $0,5 \%$ dos termos avaliados em cada uma das suas respectivas apostilas. A seguir, no Gráfico 1, apresentase o percentual de ocorrência de sinais e de datilologia por apostila e aplicativo.

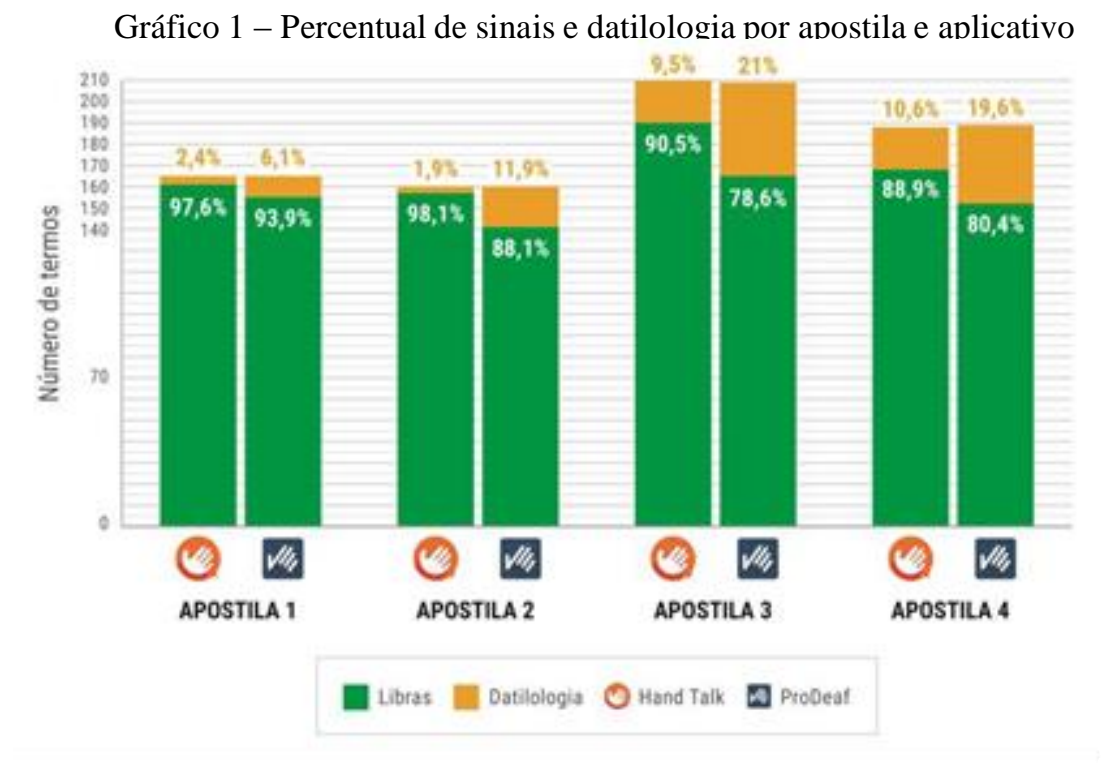

Fonte: Elaborado pelos autores.

Por meio do Gráfico 1, infere-se que, na medida em que o vocabulário das apostilas (Goiás, 2011a, 2011b, 2011c, 2011d) é apresentado em nível crescente de complexidade 
(I a IV), então é possível notar que o percentual de datilologia na conversão feita pelos aplicativos aumenta. A análise evidencia que os percentuais de datilologia do ProDeaf Móvel são maiores que os do Hand Talk. Por outro lado, entende-se que os percentuais de datilologia nos aplicativos são menores do que os de sinais em Libras, o que favorece sua utilização em contextos educacionais de ensino e aprendizagem bilíngue para surdos em sua língua materna. Supõe-se, frente aos dados analisados, que o vocabulário em Libras nas apostilas nos níveis mais avançados, apontaria, possivelmente, a mesma lógica de incidência de datilologia, sendo esta uma hipótese resultante desta pesquisa. Relativo ao total de 724 termos analisados, o aplicativo Hand Talk apresentou 676 termos em sinais e 47 termos em datilologia. Em contrapartida, o aplicativo ProDeaf Móvel apresentou 613 termos em sinais e 110 termos em datilologia. Portanto, notou-se maior recorrência de datilologia no aplicativo ProDeaf Móvel. A seguir, no Gráfico 2, são apresentados os percentuais totais em relação a cada aplicativo.

Gráfico 2 - Percentual de sinais e datilologia do total de termos analisados

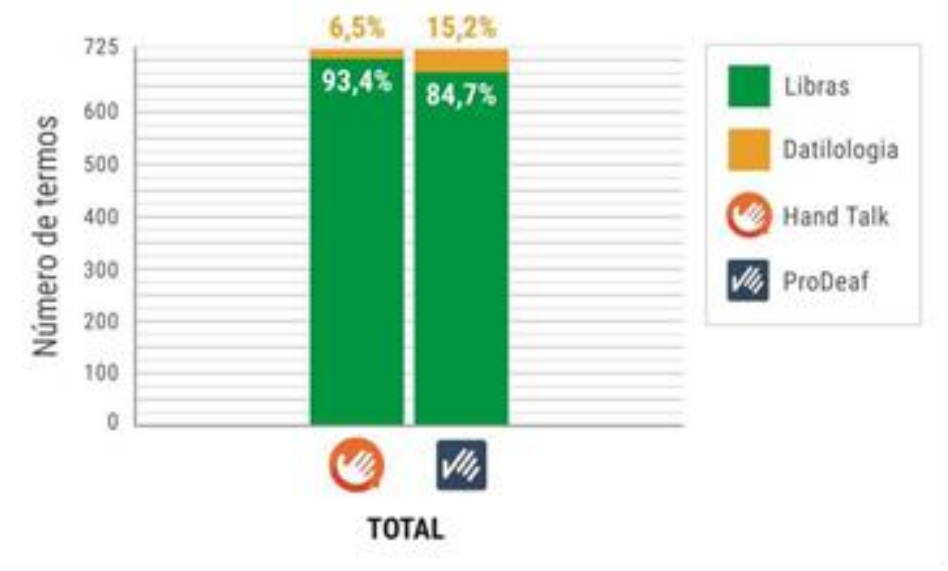

Fonte: Elaborado pelos autores.

Embora este estudo não tenha como premissa a análise da variação composicional dos parâmetros que formam um sinal em Libras (ver seção 2 - Vieira et al., 2014c), observou-se que ambas as ferramentas conversoras apresentaram variações para a formação de determinados sinais, seja pelo uso de mais de uma mão, diferente orientação e/ou movimento, assim como expressões faciais enfáticas. Nesta perspectiva, constatou-se que, diante do percentual de $93,4 \%$ de sinais em Libras, o aplicativo Hand Talk apresentou 273 termos $(37,8 \%)$ com variação de parâmetros, assim como o ProDeaf Móvel, frente ao total de 84,7\% de sinais, evidenciou 282 termos $(39,1 \%)$ sob a mesma condição. Esses dados apontam para especificidades relativas à variação linguística em Libras.

Além disso, identificou-se a incidência de termos homônimos, de mesma escrita e diferente significado, sendo estes, no caso da Língua Portuguesa, classificados como: (a) homônimos perfeitos, quando de mesma escrita e pronúncia - ex. como (pronome interrogativo), maneira, jeito, e como (verbo), ingerir algo -, e (b) homógrafos, quando de mesma escrita e diferente pronúncia - ex. colher (substantivo), utensílio doméstico, e colher (verbo), apanhar frutos. Frente a essa constatação, tais termos foram tratados como sinais, considerando o objetivo central do estudo - identificar sinais e episódios de datilologia. No entanto, foram compreendidos como em dissonância para com o conteúdo da(s) apostila(s), aspecto que exige abordagens futuras e delineadas especificamente sob este viés. Na próxima seção, apresenta-se a perspectiva acerca dos resultados e encaminhamentos futuros. 


\section{Considerações finais}

Frente aos resultados, tendo em vista que os aplicativos analisados comportam em si uma língua visuoespacial de significativa complexidade, os percentuais de datilologia foram inferiores à hipótese inicial. Por outro lado, a pesquisa corrobora a referência à presença de datilologia nos processos de conversão dos aplicativos, como mencionado nos estudos de Corrêa et al. (2014a; 2014b) e Vieira et al. (2014b), assim como em relação aos fragmentos discursivos dos professores. Contudo, a análise dos 724 termos evidenciou a predominância de sinais em Libras frente ao percentual de datilologia. Esse aspecto permite considerar que Tecnologias Assistivas digitais (Brasil, 2009; Cook; Hussey, 1995), como os aplicativos em questão, podem contribuir com o desenvolvimento social e linguístico dos surdos, democratizar o acesso à informação e fortalecer processos educacionais bilíngues, conforme mencionado nos estudos de Corrêa et al. (2014a; 2014b); Vieira et al. (2014b). No entanto, compreende-se que os aplicativos precisam aprimorar o processo de tradução de Língua Portuguesa para Libras, como forma de aproximar os usuários ao léxico da Libras, composto por sinais, evitando assim a utilização de datilologia - soletração manual - para a tradução de termos que possuem sinalização específica em Libras. Considera-se que a Libras estará sendo representada como língua natural da comunidade surda (Quadros; Karnopp, 2004) na interface dos aplicativos, na medida em que a tradução LP-Libras estiver adequada, promovendo, assim, o uso efetivo destas ferramentas digitais.

Sob o viés da aprendizagem móvel (Danesh, 2001; Consolo; Silva, 2008), os aplicativos Hand Talk e ProDeaf Móvel, na dinâmica BYOD (Vieira; Conforto, 2015) e considerando a massiva presença de smartphones (FGV-SP, 2018), podem representar estratégias de inserção de novas tecnologias na sala de aula bilíngue, conforme sugerido por Rangel e Stumpf (2015). Deste modo, tais tecnologias podem auxiliar alunos e professores em processos de ensino e aprendizagem de Libras e em espaços sociais cotidianos, nos quais podem servir para fomentar processos de autonomia e de inserção social, rompendo com possíveis delimitações espaço-temporais e desterritorializando o uso da tecnologia, como inferem Vieira e Conforto (2015). No que tange à utilização dos aplicativos em sala de aula bilíngue, entende-se que as duas ferramentas analisadas podem ser utilizadas como recursos digitais complementares para fins de consulta ao léxico da Libras, mesmo que ainda em caráter dicionarizado (Corrêa; Gomes; Ribeiro, 2017; Corrêa; Gomes; Cruz, 2018), em qualquer lugar e a qualquer momento (Danesh, 2001; Consolo; Silva, 2008; Vieira; Conforto, 2015). Relativo aos achados do presente estudo, tem-se por objetivo encaminhá-los às empresas desenvolvedoras dos aplicativos para fins de aprimoramento do processo de tradução.

1 Disponíveis em: <http://www.handtalk.me> e <http://www.prodeaf.net>. Acesso em mai. 2017.

2 GOIÁS (Estado). Secretaria da Educação. Centro de Capacitação de Profissionais da Educação e de Atendimento às Pessoas com Surdez. Apostila Libras [I, II, III, IV]. Goiás, 2011. Elaboradas a partir de parceria entre o Ministério da Educação e Cultura (MEC), a Secretaria de Educação Especial (SEESP) e a Secretaria de Estado da Educação de Goiás (SEE) através da Superintendência de Ensino Especial-SUEE.

\section{Referências}

BARBOSA, S.; SILVA, B. S. Interação Humano-Computador. RJ: Elsevier, 2010.

BARDIN, L. Análise de conteúdo. Lisboa: Ed. 70, 2007.

BERSCH, R.; TONOLli, J. C. Tecnologia Assistiva. 2006. Disponível em: <http://www.tecnologiaassistiva.com.br> Acesso em mai. 2017. 
BRASIL. Lei $\mathbf{n}^{\mathbf{0}} \mathbf{1 0 . 4 3 6}$, de 24 de abril de 2002. Dispõe sobre a Língua Brasileira de Sinais - Libras e dá outras providências. Diário Oficial da União, Brasília, DF, 25 abr. 2002, Seção 1, n. 79, p. 23, 2002.

. Subsecretaria Nacional de Promoção dos Direitos da Pessoa com Deficiência. Comitê de Ajudas Técnicas. Tecnologia Assistiva. Brasília: CORDE, 2009. 138 p.

CASALLI, A. C. P.; COSTA, C. C. V. Habilidades sociais de alunos surdos na perspectiva de professores da classe bilíngue, da classe comum e intérprete. Revista Educação Especial, Santa Maria, v. 30, n. 57, p. 55-68, jan./abr. 2017. Disponível em: <http://www.ufsm.br/revistaeducacaoespecial> Acesso em mai. 2017.

CONSOLO, A. T.; SILVA, M. G. M. Mobile Learning - uso de dispositivos móveis como auxiliar na mediação pedagógica de cursos a distância. In: 60 ${ }^{\mathbf{a}}$ Reunião Anual da SBPC, 2008. Disponível em: <http://sbpcnet.org.br/livro/60ra/resumos/resumos/R46751.html> Acesso em abr. 2017.

COOK, A.M.; HUSSEY, S. M. Assistive Technologies: Principles and Practices. St. Louis, Missouri. Mosby - Year Book, Inc., 1995.

CORRÊA, Y.; VIEIRA, M. C.; SANTAROSA, L. M. C.; BIAZUS, M. C. V. Tecnologia Assistiva: a inserção de aplicativos de tradução na promoção de uma melhor comunicação entre surdos e ouvintes. RENOTE - Revista Novas Tecnologias na Educação, v. 12, p. 1-10, 2014a.

Aplicativos de tradução para Libras e a busca pela validade social da Tecnologia Assistiva. In: XXV Simpósio Brasileiro de Informática na Educação (SBIE 2014), 2014b, Dourados. Sociedade Brasileira de Computação SBC, p. 164-173.

CORRÊA, Y.; GOMES, R. P.; CRUZ, C. R. A desambiguação de palavras homônimas em sentenças por aplicativos de Tradução Automática Português Brasileiro-Libras. Revista Trabalhos de Linguística Aplicada, Campinas, v. 57, jan./abr., n. 1, 2018.

CORRÊA, Y.; GOMES, R. P.; RIBEIRO, V. G. Aplicativos de Tradução PortuguêsLibras na Educação Bilíngue: desafios frente à desambiguação. RENOTE - Revista Novas Tecnologias na Educação, v. 15, n. 2, p. 1-10, 2017.

CRUZ, S. R.; ARAÚJO, D. A. C. A história da educação de alunos com surdez: ampliação de possibilidades? Revista Educação Especial, Santa Maria, v. 29, n. 55, p. 373-384, maio/ago. 2016. Disponível em: <http://www.ufsm.br/revistaeducacaoespecial> Acesso em abr. 2017.

DANESH, A.; INKPEN, K.; LAU F., SHU, K.; BOOTH, K. (2001) Geney: designing a collaborative activity for the Palm handheld computer. In: CONFERENCE ON HUMAN FACTORS IN COMPUTING SYSTEMS.

FUNDAÇÃO GETÚlIO VARGAS DE SÃO PAULO (FGV-SP). Escola de Administração de Empresas de São Paulo. 29a Pesquisa Anual de Administração e Uso de Tecnologia da Informação nas Empresas. 2018. Disponível em: <https://eaesp.fgv.br/sites/eaesp.fgv.br/files/pesti2018gvciappt.pdf>. Acesso em: jul. 2018 .

GESSER, A. LIBRAS? Que língua é essa?: crenças e preconceitos em torno da língua de sinais e da realidade surda. São Paulo: Parábola, 2009. 
KELMAN, C. A. Multiculturalismo e surdez: respeito às culturas minoritárias. In: LODI, A. C. B.; MÉLO, A. D. B.; FERNANDES, E. (Orgs.). Letramento, bilinguismo e Educação de Surdos. Porto Alegre, Mediação, 2015.

QUADROS, R. M. de; KARNOPP, L. B. Língua de sinais brasileira: estudos linguísticos. Porto Alegre: Artmed, 2004.

RANGEL, G. M. M.; STUMPF, M. R. A pedagogia da diferença para o surdo. In: LODI, A. C. B.; MÉLO, A. D. B. de; FERNANDES, E. (Orgs.). Letramento, bilinguismo e Educação de Surdos. Porto Alegre, Mediação, 2 ed., 2015.

SAMPIERI, R. H.; COLlADO, C. F.; LUCIO, M. del P. B. Metodologia de Pesquisa. Porto Alegre: Ed. Penso, 2013.

SILVA, A. C. A representação Social da Surdez: entre o mundo acadêmico e o cotidiano escolar. In: LODI, A. C. B.; MÉLO, A. D. B. de; FERNANDES, E. (Orgs.). Letramento, bilinguismo e Educação de Surdos. Porto Alegre, Mediação, 2 ed., 2015 .

SOARES, F. M. R. O (não) ser surdo em escola regular: um estudo sobre a construção da identidade. In: LODI, Ana Claudia Balieiro; MÉLO, A. D. B. de; FERNANDES, E. (Orgs.). Letramento, bilinguismo e Educação de Surdos. Porto Alegre, Mediação, 2 ed., 2015.

VIEIRA, M. C.; CONFORTO, D. Aprendizagem Móvel e Multimídia: a produção de material pedagógico na perspectiva BYOD. In: XXI Workshop de Informática na Escola (WIE 2015). Anais... 2015. p. 82-91. DOI: 10.5753/cbie.wie.2015.82

VIEIRA, M. C.; CORRÊA, Y.; CHEIRAN, J. F. P.; SANTAROSA, L. M. C.; BIASUZ, Maria C. V. Contribuições da Teoria da Aprendizagem Multimídia e da Usabilidade para aprendizagem de Libras e Língua Portuguesa por meio de aplicativos móveis. RENOTE - Revista Novas Tecnologias na Educação, v. 12, p. 1-10, 2014a.

VIEIRA, M. C.; CORRÊA, Y.; SANTAROSA, L. M. C.; BIAZUS, M. C. V. Além da interação: tradutores automáticos para língua de sinais e a constituição do sujeito surdo. In: International Society for Augmentative and Alternative Communication ISAAC, Lisboa, Portugal. 2014b.

Análise de expressões não-manuais em avatares tradutores de Língua Portuguesa para Libras. In: XIX Conferência Internacional sobre Informática na Educação - TISE, 2014, Fortaleza. Nuevas Ideas en Informática Educativa, 2014c. v. 10. p. 172-183. 